\title{
Development and validation of a prognostic nomogram for Hürthle cell thyroid carcinoma: a SEER-based study
}

\author{
Cong Shen ${ }^{1 \#}$, Yunzhe Zhao ${ }^{1 \#}$, Xiangyuan Qiu ${ }^{1 \#}$, Peng Li $^{1}$, Ying Ding ${ }^{1}$, Wenlong Wang ${ }^{1}$, Botao Sun ${ }^{1}$, \\ Xinying Li ${ }^{1,2}$, Wei Jiang ${ }^{1,2}$ \\ ${ }^{1}$ Department of General Surgery, Xiangya Hospital, Central South University, Changsha, China; ${ }^{2}$ National Clinical Research Center for Geriatric \\ Disorders, Xiangya Hospital, Central South University, Changsha, China \\ Contributions: (I) Conception and design: X Li; (II) Administrative support: X Li; (III) Provision of study materials or patients: C Shen, Y Zhao, X \\ Qiu; (IV) Collection and assembly of data: All authors; (V) Data analysis and interpretation: C Shen, Y Zhao, X Qiu; (VI) Manuscript writing: All \\ authors; (VII) Final approval of manuscript: All authors. \\ \#These authors contributed equally to this work. \\ Correspondence to: Xinying Li, MD. Department of General Surgery, Xiangya Hospital, Central South University, Changsha 410008, China. \\ Email: lixinyingcn@126.com; Wei Jiang, MD. Department of General Surgery, Xiangya Hospital, Central South University, Changsha 410008, \\ China. Email: 29557291@qq.com.
}

Background Hürthle cell carcinoma is a rare subtype of thyroid cancer, and its clinical behavior and
biological characteristics remain unclear. This study aimed to establish nomogram models for the prognostic
evaluation of Hürthle cell thyroid carcinoma (HCTC) in terms of both cancer-specific survival (CSS) and
overall survival (OS).
Methods: Data for a total of 3,264 patients with HCTC (2004 to 2018) were extracted from the
Surveillance, Epidemiology, and End Results (SEER) database. Univariate and multivariate Cox regression
analysis was performed to identify significant predictors of prognosis and develop a prognostic nomogram.
The performance of the model was assessed based on the area under the receiver operating characteristic
curve (AUC), concordance index (c-index), and calibration curves. Results: Multivariate Cox regression analysis showed that age, sex, summary stage, tumor size, N stage, M stage, and treatment with thyroidectomy were independent predictors of OS. Moreover, age, summary stage, tumor size, $\mathrm{N}$ stage, $\mathrm{M}$ stage, AJCC stage, and treatment with thyroidectomy were significantly correlated with CSS. The c-index of the OS and CSS nomograms developed based on these factors was 0.822 (95\% CI: $0.803-0.841$ ) and 0.893 (95\% CI: 0.866-0.920), respectively. The AUC was 0.888, 0.841, and 0.834 for 1-, 3-, and 5-year OS and $0.970,0.949$, and 0.933 for 1-, 3-, and 5-year CSS, respectively. The calibration curves showed good agreement between observed and predicted values. Moreover, decision curve analysis revealed that the nomogram had a better clinical utility than individual clinicopathological markers.

Conclusions: A prognostic nomogram that allows the individualized assessment of OS and CSS in HCTC was developed. This nomogram could be used to guide treatment decisions in patients with HCTC.

Keywords: Hürthle cell carcinoma; nomogram; overall survival (OS); cancer-specific survival (CSS); Surveillance, Epidemiology, and End Results database (SEER database)

Submitted Nov 21, 2021. Accepted for publication Jan 24, 2022.

doi: $10.21037 /$ gs-21-781

View this article at: https://dx.doi.org/10.21037/gs-21-781

\section{Introduction}

Thyroid cancer is the most common endocrine malignancy. This tumor originates from the thyroid follicular epithelium or parafollicular epithelial cells. The latest statistics show that the incidence of thyroid cancer has rapidly increased worldwide in the past few decades, moreover, this malignancy has also shown an obvious sex preponderance (1-5). Hürthle cell thyroid carcinoma (HCTC), a special 
type of thyroid tumor, accounts for approximately 3-4\% of all thyroid cancer cases. Owing to its unique biological behavior and genetic characteristics (6), HCTC has been classified separately from follicular thyroid cancer (FTC) in the latest version of the World Health Organization (WHO) Classification of Tumors (7).

Compared with other differentiated thyroid cancers, HCTC typically shows more aggressive behavior, including higher rates of lymph node and distant metastases $(8,9)$. The clinical presentation of HCTC is similar to that of FTC, and most patients present with a single painless thyroid nodule, hoarseness, and dysphagia. The preoperative diagnosis of HCTC through radiology or fine needle aspiration (FNA) is challenging. Currently, the histological evaluation of surgical specimens is the best approach for HCTC diagnosis (10). As for other differentiated thyroid cancers, surgical resection is the mainstay for HCTC treatment. Typically, diagnostic lobectomy is the first choice, and decisions on further surgical resection are taken based on the histological diagnosis (11). The efficacy of radioactive iodine (RAI) therapy for HCTC is currently unclear. Jillard et al. (12) suggested that RAI improves survival in HCTC patients. However, other studies have shown that the uptake of radioactive iodine by HCTC tumors is poor, and HCTC is not sensitive enough to show a good response to radiotherapy and chemotherapy $(13,14)$. Therefore, a consensus on the optimal management of patients with HCTC is currently lacking. At present, the prognostic factors for HCTC remain to be fully elucidated $(15,16)$. The early identification of high-risk HCTC patients is crucial for improving prognosis. Hence, it is necessary to obtain accurate information on survival-related factors and to develop a prognostic model.

The Surveillance, Epidemiology, and End Results (SEER) database is the authoritative cancer statistics database in the United States and has a large sample size. Research based on the SEER database has a high clinical reference value. In the present study, data from the SEER database were used to identify predictors of overall survival (OS) and cancer-specific survival (CSS) in patients with HCTC using univariate and multivariate Cox regression analyses. The study aimed to establish nomogram models for the prognostic evaluation of HCTC in order to improve the clinical management of HCTC patients.

We present the following article in accordance with the TRIPOD reporting checklist (available at https:// gs.amegroups.com/article/view/10.21037/gs-21-781/rc).

\section{Methods}

\section{Data selection}

Data on patients with HCTC (Site recode ICD-O-3/WHO 2008 coded as Thyroid and AYA site recode 2020 Revision coded as Hürthle cell carcinoma) treated between 2004 and 2018 were obtained from the SEER database: Incidence SEER Research Data, 18 Registries, Nov 2020 Sub (20002018). We focused on factors such as sex, year of diagnosis, race, laterality, diagnostic confirmation, Histological type, combined summary stage, surgery status, tumor size, cause of death, cancer-specific death, survival duration, vital status (study cutoff used), AJCC stage group, AJCC T stage, AJCC N stage, AJCC $M$ stage, age at diagnosis, Grade (through 2017), metastasis at bone, metastasis at brain, metastasis at liver, and metastasis at lung. Only patients with histologically confirmed HCTC were included. Patients for whom detailed basic information such as race, combined summary stage, tumor size, surgery status, and AJCC stage were not known $(\mathrm{n}=443)$ were excluded from the analysis cohort (Figure 1). The study was conducted in accordance with the Declaration of Helsinki (as revised in 2013).

\section{Statistics analysis}

Statistical analysis was performed using the R software (version 3.4.2) and SPSS 22.0 (IBM Corp., Armonk, NY, USA). Categorical variables were expressed as counts and percentages, whereas continuous variables were expressed as means and ranges. Univariate and multivariate Cox analysis was performed to identify significant predictors and develop a prognostic nomogram. The performance of the models was assessed based on the area under the receiver operating characteristic curve (AUC), concordance index (c-index), and calibration curves. A calibration plot (with bootstrapping) was used to examine the association between actual and predicted survival probabilities. The clinical usefulness of the nomogram was evaluated using decision curve analysis (DCA). All tests were two-sided, and $\mathrm{P}<0.05$ was considered statistically significant.

\section{Results}

\section{Demographic and clinical characteristics}

Data on a total of 3,264 patients with HCTC (2004 to 2018) were extracted from the SEER database. Female patients 


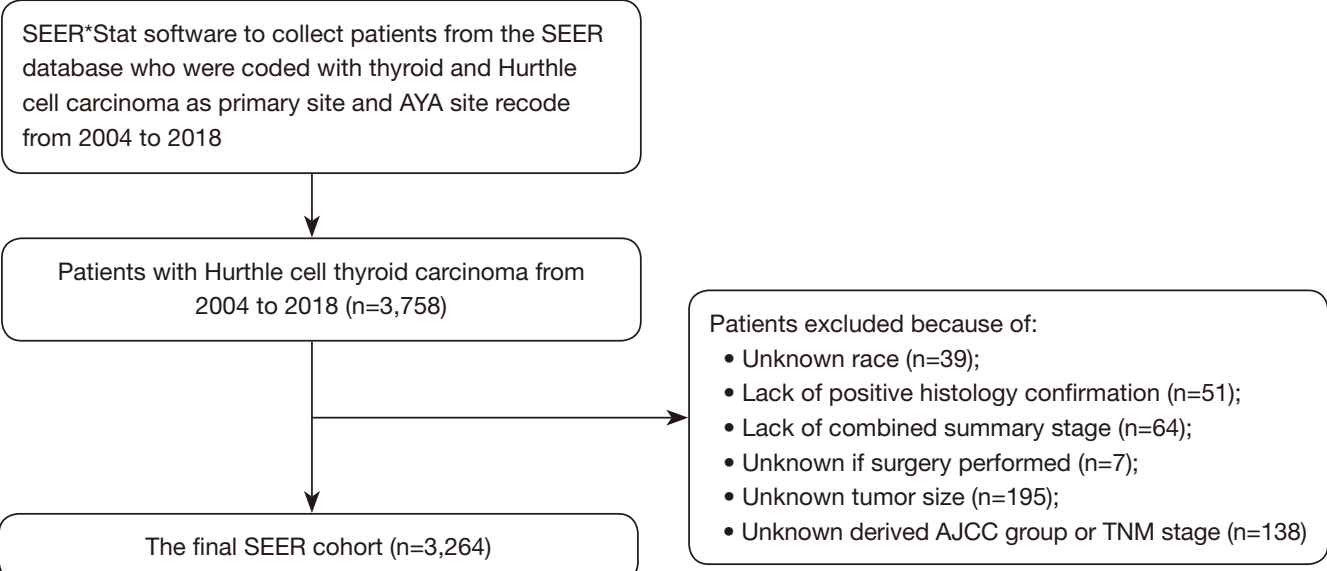

SEER ${ }^{*}$ Stat software to collect patients from the SEER ell carcinoma as primary site and AYA site recode

The final SEER cohort $(n=3,264)$

Figure 1 Flowchart of data selection.

accounted for a majority of the study cohort (68.3\%; male patients, $31.7 \%)$. The median age of the study cohort was 58 years. Most patients were 55 years old and above (58.6\%), whereas patients below the age of 55 accounted for $41.4 \%$ of the cohort. Moreover, most patients were White $(84.8 \%$ of all patients). Localized metastasis was the most common (2,749 patients, $84.2 \%)$, followed by regional (11.7\%) and distant metastases (4.0\%). Further, the median tumor size was $31.5 \mathrm{~mm}$. With respect to tumor stage, 138 patients (4.2\%) showed T4 stage disease, 184 (5.6\%) showed N1 stage disease, and $90(2.8 \%)$ showed M1 stage disease. Moreover, there were 220 patients $(6.7 \%)$ with AJCC stage IV disease. Of these patients, 3,223 (98.7\%) had undergone thyroidectomy, while $41(1.3 \%)$ did not undergo surgery. The detailed clinical characteristics are shown in Table 1.

\section{Construction of nomogram}

The univariate and multivariate Cox regression analyses were employed to identify the predictive factors of OS and CSS in HCTC patients. As shown in Table 2, the age at diagnosis, sex, race, summary stage, tumor size, T stage, $\mathrm{N}$ stage, $\mathrm{M}$ stage, AJCC stage, and treatment with thyroidectomy were all included in the analysis. The univariate Cox analysis indicated that age, sex, summary stage, tumor size, $\mathrm{T}$ stage, $\mathrm{N}$ stage, $\mathrm{M}$ stage, AJCC stage, and treatment with thyroidectomy were all predictive factors for both OS and CSS. However, multivariate Cox analysis showed that age, sex, summary stage, tumor size, $\mathrm{N}$ stage, $\mathrm{M}$ stage, and treatment with thyroidectomy were independent predictors of OS. In contrast, summary stage, tumor size, $\mathrm{N}$ stage, $\mathrm{M}$ stage, AJCC stage, and treatment thyroidectomy were independent predictive factors for CSS. Therefore, Cox analysis findings indicated that HCTC patients who were older; had distant metastasis, larger tumors, and N1 and M1 stage disease; and did not undergo thyroidectomy had a poorer prognosis. Therefore, we constructed separate nomograms for OS and CSS (Figure 2) in order to predict the 1-, 3- and 5-year survival probability in HCTC patients.

\section{Validation of nomogram}

To assess the discrimination value of the nomograms, we calculated c-indexes. The c-index of the OS and CSS nomogram was 0.822 (95\% CI: $0.803-0.841)$ and 0.893 (95\% CI: 0.866-0.920), respectively. Calibration curves showed a good consistency between the predicted and actual values of 1-, 3-, and 5-year OS and CSS in patients with HCTC (Figure 3). These findings were consistent with those of AUC analysis. The AUCs were $0.888,0.841$, and 0.834 for 1-, 3-, and 5-year OS and 0.970, 0.949, and 0.933 for 1-, 3-, and 5-year CSS, respectively (Figure 4). In addition, DCA indicated that the nomogram provided better clinical utility than individual clinical features (Figure 5). These results showed that the nomograms were accurate and reliable for the prediction of survival outcomes in HCTC.

\section{Discussion}

HCTC is now independently classified and is considered separate from FTC (17). HCTC is more aggressive than FTC and is associated with a worse prognosis $(18,19)$. HCTC patients also show a higher metastasis rate and 
Table 1 Characteristics of patients from SEER database

\begin{tabular}{|c|c|}
\hline Variables & Total $(\mathrm{N}=3,264)$ \\
\hline \multicolumn{2}{|l|}{ Sex } \\
\hline Female & 2,228 (68.3\%) \\
\hline Male & $1,036(31.7 \%)$ \\
\hline \multicolumn{2}{|l|}{ Age (years) } \\
\hline Mean (SD) & $57.5(15.5)$ \\
\hline Median [min, max] & $58.0[11.0,85.0]$ \\
\hline \multicolumn{2}{|l|}{ Age group (years) } \\
\hline$<55$ & $1,351(41.4 \%)$ \\
\hline$\geq 55$ & 1,913 (58.6\%) \\
\hline \multicolumn{2}{|l|}{ Race } \\
\hline Black & $273(8.4 \%)$ \\
\hline Other & $223(6.8 \%)$ \\
\hline White & 2,768 (84.8\%) \\
\hline \multicolumn{2}{|l|}{ Summary stage } \\
\hline Distant & $132(4.0 \%)$ \\
\hline Localized & 2,749 (84.2\%) \\
\hline Regional & 383 (11.7\%) \\
\hline \multicolumn{2}{|l|}{ Tumor size (mm) } \\
\hline Mean (SD) & $36.6(23.2)$ \\
\hline Median [min, max] & $31.5[0,420]$ \\
\hline \multicolumn{2}{|l|}{ T stage } \\
\hline $\mathrm{T} 1$ & $821(25.2 \%)$ \\
\hline T2 & $1,164(35.7 \%)$ \\
\hline T3 & $1,141(35.0 \%)$ \\
\hline $\mathrm{T} 4$ & $138(4.2 \%)$ \\
\hline \multicolumn{2}{|l|}{$\mathrm{N}$ stage } \\
\hline No & 3,080 (94.4\%) \\
\hline $\mathrm{N} 1$ & $184(5.6 \%)$ \\
\hline \multicolumn{2}{|l|}{ M stage } \\
\hline MO & $3,174(97.2 \%)$ \\
\hline M1 & $90(2.8 \%)$ \\
\hline
\end{tabular}

Table 1 (continued)
Table 1 (continued)

\begin{tabular}{lc}
\hline Variables & Total $(\mathrm{N}=3,264)$ \\
\hline AJCC stage & $1,328(40.7 \%)$ \\
I & $886(27.1 \%)$ \\
II & $830(25.4 \%)$ \\
III & $220(6.7 \%)$ \\
IV & \\
Thyroidectomy & $41(1.3 \%)$ \\
No & $3,223(98.7 \%)$ \\
Yes
\end{tabular}

SEER, Surveillance, Epidemiology, and End Results; AJCC, American Joint Committee on Cancer.

lower OS and disease-specific survival (20-22). HCTC is more common than other types of differentiated thyroid cancers among men $(31.1 \%$ vs. $23.0 \%, \mathrm{P}<0.001)$ and older patients (mean age, 57.6 years vs. 48.9 years, $\mathrm{P}<0.001)(8)$. Despite the prognostic difference between HCTC and FTC, HCTC cannot be considered a highly aggressive carcinoma. In the present study, a small proportion of HCTC patients were diagnosed at an advanced stage (T4 stage, $4.2 \%$; N1 stage, 5.6\%; and M1 stage, $2.8 \%$ ), and most of them underwent surgery.

The present study showed that age, sex, treatment with thyroidectomy, summary stage, tumor size, $\mathrm{N}$ stage, and $\mathrm{M}$ stage are associated with the prognosis of HCTC. The link between older age and a worse survival has been proven by many studies (23). In a cohort of 89 HCTC patients from the United States, age $>45$ years was found to be correlated with reduced survival. However, age was not identified as an independent risk factor for poor survival in the multivariate analysis (24). By dividing HCTC patients into different age groups ( $<45$ years, $45-64$ years, and $\geq 65$ years), one study (8) found that age was negatively correlated with disease-specific survival and was an independent prognostic factor in the last two groups. In the present study, age was identified as an independent risk factor, and the median age in the study cohort was 58 years. This suggested that most HCTC patients in the cohort would require aggressive 
Table 2 Univariate and multivariate Cox analysis of OS and CSS

\begin{tabular}{|c|c|c|c|c|c|c|c|c|}
\hline \multirow{2}{*}{ Variables } & \multicolumn{4}{|c|}{ OS } & \multicolumn{4}{|c|}{ CSS } \\
\hline & $\mathrm{HR}(95 \% \mathrm{Cl})$ & $P$ value & $\mathrm{HR}(95 \% \mathrm{Cl})$ & $P$ value & $\mathrm{HR}(95 \% \mathrm{Cl})$ & $P$ value & $\mathrm{HR}(95 \% \mathrm{Cl})$ & $P$ value \\
\hline Age (years) & $1.09(1.08,1.10)$ & $<0.001$ & $1.08(1.07,1.09)$ & $<0.001$ & $1.07(1.05,1.08)$ & $<0.001$ & $1.04(1.02,1.05)$ & $<0.001$ \\
\hline \multicolumn{9}{|l|}{ Sex } \\
\hline Male & $1.86(1.56,2.21)$ & $<0.001$ & $1.27(1.06,1.53)$ & 0.011 & $1.73(1.24,2.42)$ & 0.001 & $0.86(0.61,1.23)$ & 0.409 \\
\hline \multicolumn{9}{|l|}{ Race } \\
\hline Black & 1 (ref) & & & & 1 (ref) & & & \\
\hline White & $0.97(0.71,1.32)$ & 0.822 & & & $1.69(0.79,3.62)$ & 0.178 & & \\
\hline Distant & 1 (ref) & & 1 (ref) & & 1 (ref) & & 1 (ref) & \\
\hline Localized & $0.11(0.08,0.14)$ & $<0.001$ & $0.46(0.24,0.85)$ & 0.014 & $0.02(0.01,0.03)$ & $<0.001$ & $0.31(0.13,0.78)$ & 0.012 \\
\hline Regional & $0.24(0.18,0.32)$ & $<0.001$ & $0.62(0.36,1.08)$ & 0.091 & $0.14(0.09,0.21)$ & $<0.001$ & $0.64(0.31,1.29)$ & 0.207 \\
\hline Tumor size (mm) & $1.01(1.01,1.01)$ & $<0.001$ & $1.01(1.00,1.01)$ & $<0.001$ & $1.01(1.01,1.01)$ & $<0.001$ & $1.01(1.01,1.02)$ & $<0.001$ \\
\hline \multicolumn{9}{|l|}{ T stage } \\
\hline $\mathrm{T} 1$ & 1 (ref) & & 1 (ref) & & 1 (ref) & & 1 (ref) & \\
\hline $\mathrm{T} 2$ & $1.21(0.93,1.59)$ & 0.162 & $0.82(0.44,1.54)$ & 0.536 & $1.07(0.48,2.38)$ & 0.872 & $0.87(0.32,2.37)$ & 0.780 \\
\hline T3 & $2.13(1.65,2.75)$ & $<0.001$ & $1.25(0.70,2.24)$ & 0.452 & $5.54(2.85,10.76)$ & $<0.001$ & $1.58(0.63,3.94)$ & 0.325 \\
\hline MO & 1 (ref) & & 1 (ref) & & 1 (ref) & & 1 (ref) & \\
\hline M1 & $9.90(7.50,13.07)$ & $<0.001$ & $2.03(1.19,3.49)$ & 0.009 & $34.36(23.87,49.46)$ & $<0.001$ & $2.80(1.44,5.47)$ & 0.003 \\
\hline \multicolumn{9}{|l|}{ AJCC stage } \\
\hline I & 1 (ref) & & 1 (ref) & & 1 (ref) & & 1 (ref) & \\
\hline II & $2.40(1.83,3.16)$ & $<0.001$ & $1.39(0.73,2.63)$ & 0.313 & $1.39(0.54,3.60)$ & 0.498 & $0.97(0.29,3.30)$ & 0.965 \\
\hline III & $3.51(2.71,4.55)$ & $<0.001$ & $0.76(0.43,1.34)$ & 0.34 & $7.72(3.76,15.86)$ & $<0.001$ & $1.93(0.73,5.10)$ & 0.183 \\
\hline IV & $13.22(9.99,17.49)$ & $<0.001$ & $0.81(0.41,1.59)$ & 0.535 & $82.40(41.34,164.27)$ & $<0.001$ & $4.74(1.57,14.32)$ & 0.006 \\
\hline Thyroidectomy & $0.10(0.06,0.16)$ & $<0.001$ & $0.29(0.18,0.49)$ & $<0.001$ & $0.06(0.03,0.10)$ & $<0.001$ & $0.30(0.15,0.60)$ & $<0.001$ \\
\hline
\end{tabular}

OS, overall survival; CSS, cancer-specific survival; HR, hazard ratio; AJCC, American Joint Committee on Cancer. 


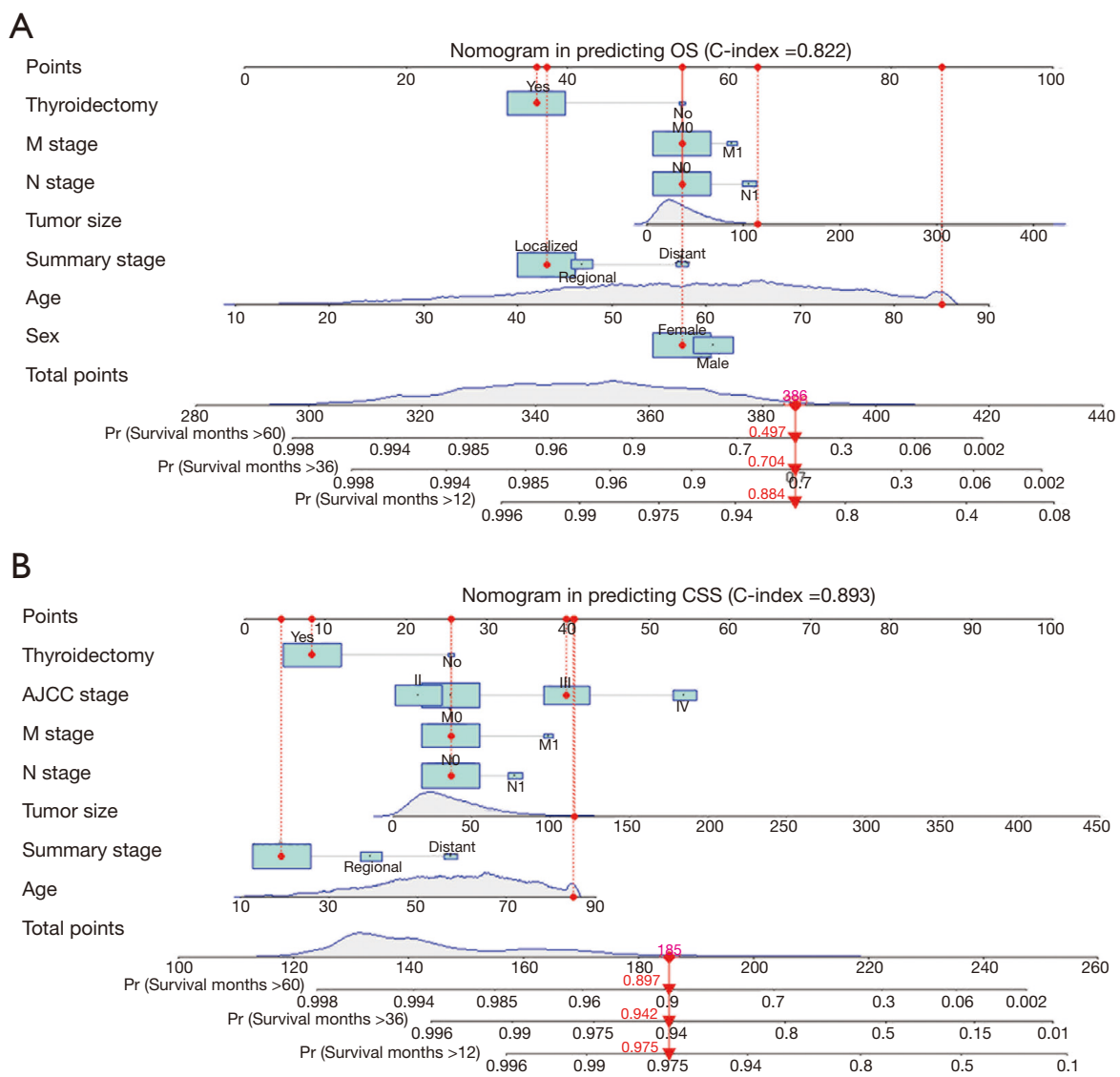

Figure 2 The nomograms of 1-, 3- and 5-year OS (A) and CSS (B) in thyroid HCTC patients. OS, overall survival; CSS, cancer-specific survival; HCTC, Hürthle cell carcinoma.
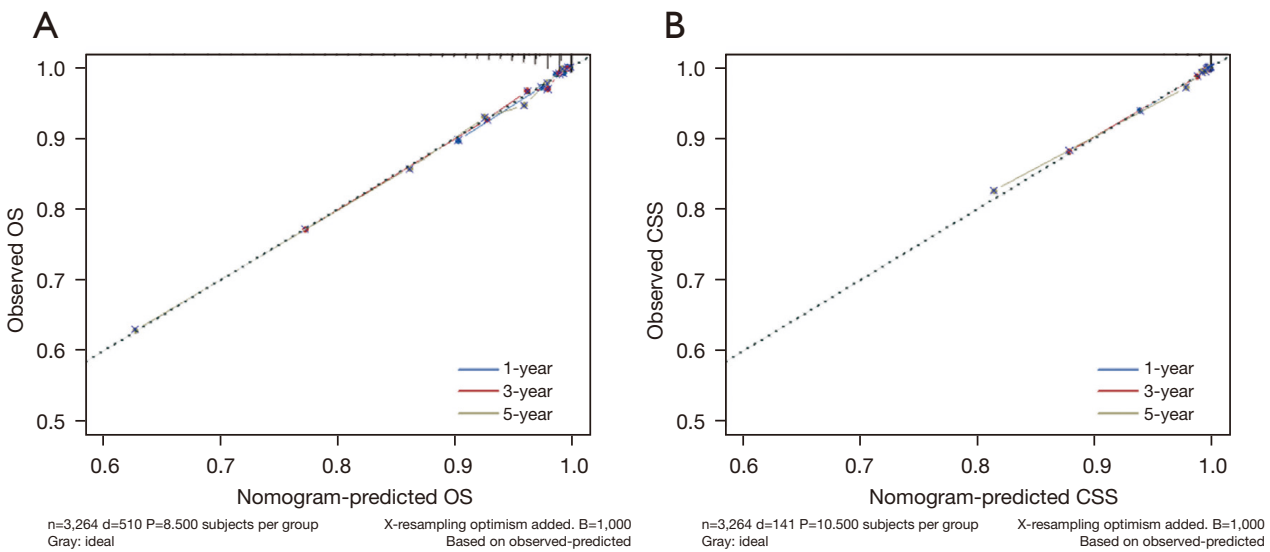

Figure 3 Calibration curves in predicting the 1-, 3- and 5-year OS (A) and CSS (B). The x-axis shows the predicted survival probability and the $y$-axis shows the actual survival probability. The 45-degree dotted line shows that the prediction agrees with actuality. OS, overall survival; CSS, cancer-specific survival. 
A

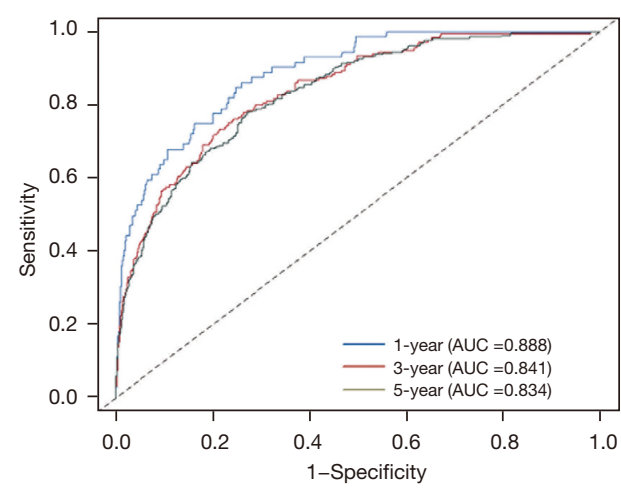

B

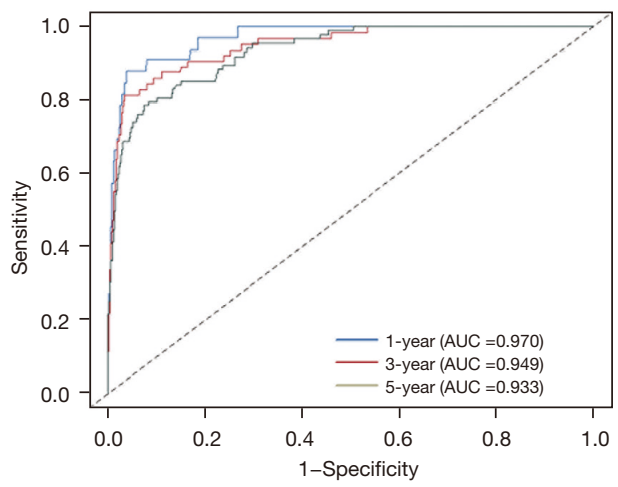

Figure 4 ROC curves and AUCs of 1-, 3- and 5-year OS (A) and CSS (B) were used to estimate the prognostic accuracy of the nomogram. ROC, receiver operator characteristic; AUC, area under the curve; OS, overall survival; CSS, cancer-specific survival.

A

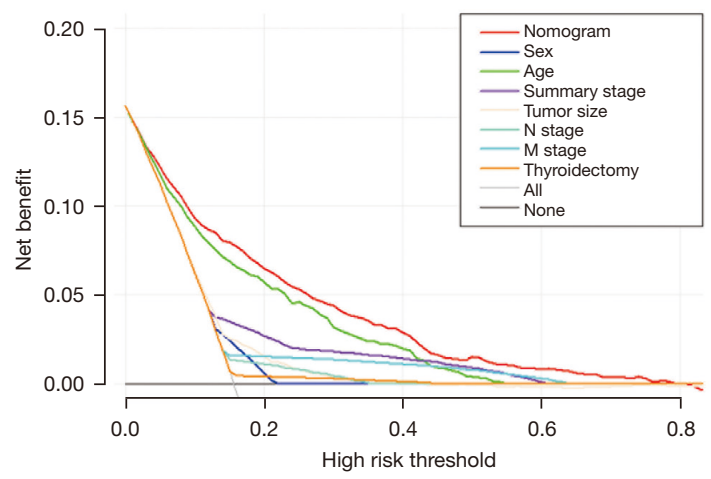

C

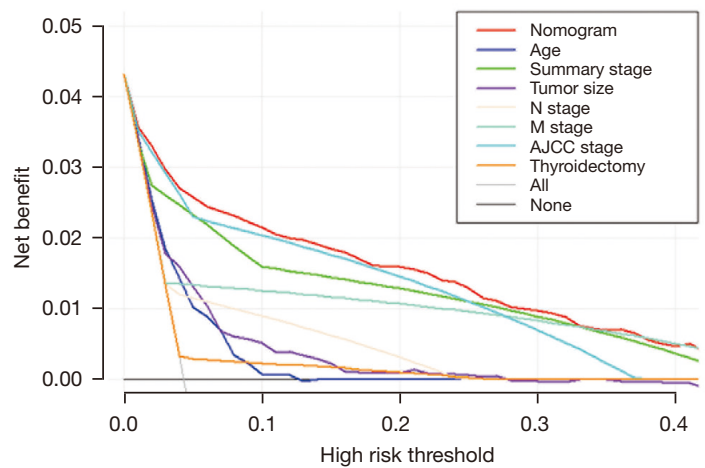

B

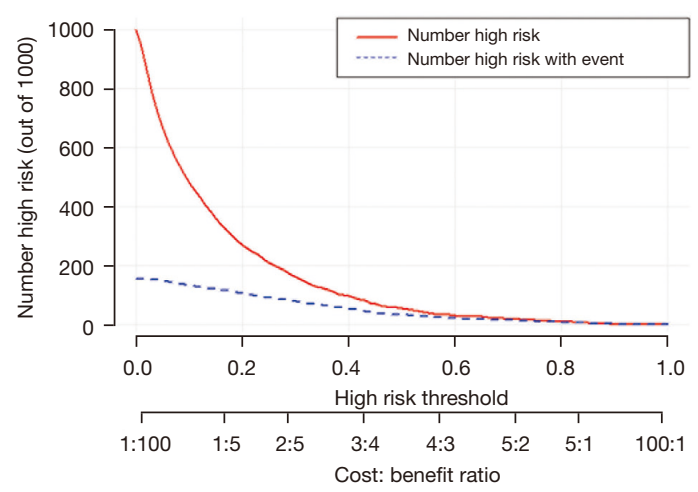

D

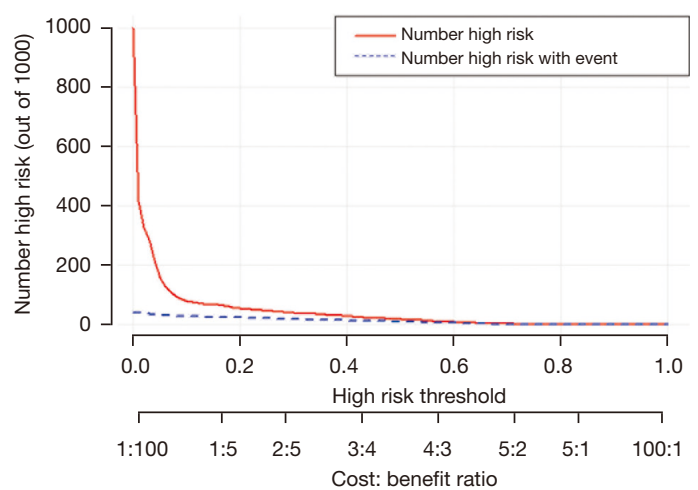

Figure 5 DCA of nomogram in predicting 1-, 3- and 5-year OS (A and B) and CSS (C and D). DCA, decision curve analysis; OS, overall survival; CSS, cancer-specific survival. 
clinical management and surveillance.

Many studies show that male sex is predictive of worse outcomes in HCTC $(16,25)$. In the present study, almost one-third of all patients were men. Male sex was an independent predictor of OS, but it did not influence CSS. Thyroidectomy is recommended for HCTC patients $(15,26,27)$, and our multivariate analysis also indicated that thyroidectomy was the strongest protective factor in HCTC. It is widely accepted that tumor size can increase the risk of poor outcomes. Using multivariate analysis, a study (8) demonstrated that a tumor size $\geq 4 \mathrm{~cm}$ was associated with a higher disease specific mortality $(\mathrm{HR}=1.89, \mathrm{P}=0.039)$. Another study (24) that used $4 \mathrm{~cm}$ as the cutoff indicated that a larger tumor size was associated with a worse outcome. The results of this study confirmed that tumor size was an independent predictor of both OS and CSS.

Nomograms are considered a graphical tool that can be used to calculate individual risk by integrating and quantifying prognostic factors (28). Accordingly, they are widely applied to assess indicators of cancer prognosis, including recurrence, metastasis, and OS (29-31). To our knowledge, this study is the first to construct an integrated prognostic nomogram for HCTC. In the study, all prognostic factors identified using multivariate Cox regression analysis were weighted and scored. The nomogram illustrated that age, tumor size, $\mathrm{N}$ stage, and $M$ stage were the most significant predictors of prognosis, while sex showed a limited influence on outcomes. This implies that clinical characteristics of patients could be used to predict 1-, 3-, and 5-year OS and CSS without any expensive tests.

The accuracy and net benefits of the developed model were also assessed in the present study. The c-index, calibration curves, and time-dependent AUC analysis were used for this purpose. The c-index of the OS and CSS nomograms was 0.822 (95\% CI: 0.803-0.841) and 0.893 (95\% CI: 0.866-0.920), respectively, indicating its excellent value. Calibration plots demonstrated a great consistency between nomogram-predicted and actual survival probabilities, which confirmed the reliability of the nomograms. Moreover, the AUCs for 1-, 3-, and 5-year OS were $0.888,0.841$, and 0.834 , respectively, and those for 1-, 3-, and 5-year CSS were 0.970, 0.949, and 0.933, respectively. Hence, near-perfect agreement was observed between predicted and actual outcomes. Additionally, the nomogram exhibited a better net benefit than individual clinical characteristics. These results showed that the nomogram possessed excellent discrimination ability and accuracy.

Nevertheless, there were some limitations to this study. First, some significant clinical parameters were not included in the model. Widely invasive HCTC had quite different prognosis compared with minimally. Tumor multifocality can increased risk of recurrence. Additionally, treatments including hemithyroidectomy, total thyroidectomy and radioactive iodine were not acquired in this study, which might function as confounders. Second, given that the study was retrospective in nature, selection bias may have occurred. Finally, the lack of external validation cohorts could have led to over-fitting effects. Therefore, efforts should be made to perform more comprehensive and prospective studies in this field.

\section{Conclusions}

The study demonstrated that age, sex, tumor size, summary stage, $\mathrm{N}$ stage, and $\mathrm{M}$ stage are independent prognostic factors for HCTC. Additionally, a novel predictive model was developed to predict the survival probability in patients with HCTC. This nomogram could be helpful for avoiding unnecessary tests and medical expenses and for identifying high-risk patients with HCTC. Therefore, the nomogram could allow improved decision-making in HCTC treatment.

\section{Acknowledgments}

All authors thank SEER database for sharing the worthy data.

Funding: This work was supported by the National Natural Science Foundation of China (Grant No. 81672885) and Innovative Foundation for graduate students of Hunan Province (Grant No. 2020zzts259).

\section{Footnote}

Reporting Checklist: The authors have completed the TRIPOD reporting checklist. Available at https:// gs.amegroups.com/article/view/10.21037/gs-21-781/rc

Conflicts of Interest: All authors have completed the ICMJE uniform disclosure form (available at https://gs.amegroups. com/article/view/10.21037/gs-21-781/coif). The authors have no conflicts of interest to declare.

Ethical Statement: The authors are accountable for all aspects of the work in ensuring that questions related 
to the accuracy or integrity of any part of the work are appropriately investigated and resolved. The study was conducted in accordance with the Declaration of Helsinki (as revised in 2013).

Open Access Statement: This is an Open Access article distributed in accordance with the Creative Commons Attribution-NonCommercial-NoDerivs 4.0 International License (CC BY-NC-ND 4.0), which permits the noncommercial replication and distribution of the article with the strict proviso that no changes or edits are made and the original work is properly cited (including links to both the formal publication through the relevant DOI and the license). See: https://creativecommons.org/licenses/by-nc-nd/4.0/.

\section{References}

1. Bray F, Ferlay J, Soerjomataram I, et al. Global cancer statistics 2018: GLOBOCAN estimates of incidence and mortality worldwide for 36 cancers in 185 countries. CA Cancer J Clin 2018;68:394-424.

2. Cabanillas ME, McFadden DG, Durante C. Thyroid cancer. Lancet 2016;388:2783-95.

3. Kitahara CM, Sosa JA. The changing incidence of thyroid cancer. Nat Rev Endocrinol 2016;12:646-53.

4. Wang W, Shen C, Zhao Y, et al. Identification and validation of potential novel biomarkers to predict distant metastasis in differentiated thyroid cancer. Ann Transl Med 2021;9:1053.

5. Wang W, Zhang Z, Zhao Y, et al. Management of Lateral Multiple-Level Metastasis in N1b Papillary Thyroid Microcarcinoma. Front Oncol 2020;10:1586.

6. Ganly I, Ricarte Filho J, Eng S, et al. Genomic dissection of Hurthle cell carcinoma reveals a unique class of thyroid malignancy. J Clin Endocrinol Metab 2013;98:E962-72.

7. Lloyd LR OR, Kloppel G, Rosai J, eds. WHO Classification of Tumours of Endocrine Organs. 4th ed. Lyon, France: WHO/IARC Press. 2017.

8. Goffredo P, Roman SA, Sosa JA. Hurthle cell carcinoma: a population-level analysis of 3311 patients. Cancer 2013;119:504-11.

9. Chindris AM, Casler JD, Bernet VJ, et al. Clinical and molecular features of Hürthle cell carcinoma of the thyroid. J Clin Endocrinol Metab 2015;100:55-62.

10. Ahmadi S, Stang M, Jiang XS, et al. Hurthle cell carcinoma: current perspectives. Onco Targets Ther 2016;9:6873-84.

11. Haugen BR, Alexander EK, Bible KC, et al. 2015 American
Thyroid Association Management Guidelines for Adult Patients with Thyroid Nodules and Differentiated Thyroid Cancer: The American Thyroid Association Guidelines Task Force on Thyroid Nodules and Differentiated Thyroid Cancer. Thyroid 2016;26:1-133.

12. Jillard CL, Youngwirth L, Scheri RP, et al. Radioactive Iodine Treatment Is Associated with Improved Survival for Patients with Hurthle Cell Carcinoma. Thyroid 2016;26:959-64.

13. Besic N, Vidergar-Kralj B, Frkovic-Grazio S, et al. The role of radioactive iodine in the treatment of Hürthle cell carcinoma of the thyroid. Thyroid 2003;13:577-84.

14. Kushchayeva Y, Duh QY, Kebebew E, et al. Comparison of clinical characteristics at diagnosis and during followup in 118 patients with Hurthle cell or follicular thyroid cancer. Am J Surg 2008;195:457-62.

15. Oluic B, Paunovic I, Loncar Z, et al. Survival and prognostic factors for survival, cancer specific survival and disease free interval in 239 patients with Hurthle cell carcinoma: a single center experience. BMC Cancer 2017;17:371.

16. Zhou X, Zheng Z, Chen C, et al. Clinical characteristics and prognostic factors of Hurthle cell carcinoma: a population based study. BMC Cancer 2020;20:407 .

17. Kakudo K, Bychkov A, Bai Y, et al. The new 4th edition World Health Organization classification for thyroid tumors, Asian perspectives. Pathol Int 2018;68:641-64.

18. Grani G, Lamartina L, Durante C, et al. Follicular thyroid cancer and Hürthle cell carcinoma: challenges in diagnosis, treatment, and clinical management. Lancet Diabetes Endocrinol 2018;6:500-14.

19. Stojadinovic A, Ghossein RA, Hoos A, et al. Hürthle cell carcinoma: a critical histopathologic appraisal. J Clin Oncol 2001;19:2616-25.

20. Ernaga Lorea A, Migueliz Bermejo I, Anda Apiñániz E, et al. Comparison of clinical characteristics of patients with follicular thyroid carcinoma and Hürthle cell carcinoma. Endocrinol Diabetes Nutr (Engl Ed) 2018;65:136-42.

21. Wenter V, Albert NL, Unterrainer M, et al. Clinical impact of follicular oncocytic (Hürthle cell) carcinoma in comparison with corresponding classical follicular thyroid carcinoma. Eur J Nucl Med Mol Imaging 2021;48:449-60.

22. Nagar S, Aschebrook-Kilfoy B, Kaplan EL, et al. Hurthle cell carcinoma: an update on survival over the last 35 years. Surgery 2013;154:1263-71; discussion 1271.

23. Guerrero MA, Suh I, Vriens MR, et al. Age and tumor size predicts lymph node involvement in Hürthle Cell Carcinoma. J Cancer 2010;1:23-6. 
24. Lopez-Penabad L, Chiu AC, Hoff AO, et al. Prognostic factors in patients with Hürthle cell neoplasms of the thyroid. Cancer 2003;97:1186-94.

25. Bhattacharyya N. Survival and prognosis in Hürthle cell carcinoma of the thyroid gland. Arch Otolaryngol Head Neck Surg 2003;129:207-10.

26. McHenry CR, Sandoval BA. Management of follicular and Hürthle cell neoplasms of the thyroid gland. Surg Oncol Clin N Am 1998;7:893-910.

27. Mills SC, Haq M, Smellie WJ, et al. Hürthle cell carcinoma of the thyroid: Retrospective review of 62 patients treated at the Royal Marsden Hospital between 1946 and 2003. Eur J Surg Oncol 2009;35:230-4.

Cite this article as: Shen C, Zhao Y, Qiu X, Li P, Ding Y, Wang W, Sun B, Li X, Jiang W. Development and validation of a prognostic nomogram for Hürthle cell thyroid carcinoma: a SEER-based study. Gland Surg 2022;11(3):535-544. doi: 10.21037/gs-21-781
28. Iasonos A, Schrag D, Raj GV, et al. How to build and interpret a nomogram for cancer prognosis. J Clin Oncol 2008;26:1364-70.

29. Rocco B, Sighinolfi MC, Sandri M, et al. A novel nomogram for predicting ECE of prostate cancer. BJU Int 2018;122:916-8.

30. Jeong SH, Kim RB, Park SY, et al. Nomogram for predicting gastric cancer recurrence using biomarker gene expression. Eur J Surg Oncol 2020;46:195-201.

31. Dong D, Fang MJ, Tang L, et al. Deep learning radiomic nomogram can predict the number of lymph node metastasis in locally advanced gastric cancer: an international multicenter study. Ann Oncol 2020;31:912-20. 